Joaquim M. Guedes, arquiteto (FAU-USP);

professor associado e diretor pedagógico do

Institut D'Architecture et Urbanisme de

Strasbourg, França, professor livre docente da

FAU/USP; presidente do Escritório Arquiteto Joaquim Guedes e Associados.

Joaquim Guedes

\title{
Conjecturas sobre o futuro da urbanização brasileira
}

Comecemos pelo destaque de que a sociedade brasileira, na última década, passou de rural a urbana. A partir de 1970 deu-se a grande virada: mais da metade da população total passou a residir nas cidades, embora exercendo às vezes seu trabalho, ainda, na área rural. Essa passagem tem um profundo significado físico, econômico, social, político, organizacional e cultural.

Para uma população de aproximadamente 120 milhões de pessoas, o Brasil deve possuir mais ou menos 70 milhões de habitantes urbanos, com uma forte concentração na região sul, onde existe um processo de ocupação intensa, tendendo a formar um conjunto megalopólico em torno do eixo Rio São Paulo, além de quase uma dezena de aglomerações metropolitanas de menor porte, muito poucas, portanto, que constituem o conjunto de nós articuladores regionais da estrutura urbana nacional.

Pode-se supor que nos próximos vinte anos a população total dobrará, e a população urbana chegará aos 170 ou 190 milhões de pessoas, com um acréscimo de 100 ou 120 milhões sobre os números apresentados no final da década de 1970. De fato, não parece estar ao alcance dos governos, nem de nossa ciência, modificar as tendềncias verificadas. Os parâmetros urbanos se têm mostrado insubmissos às formas de controle conhecidas.

Ocioso é sem dúvida discutir as causas convergentes do processo de urbanização, que se originam no campo e na cidade, nos seus espaços, economias e tecnologias de desenvolvimento e organização e que ocorre em todos os países.

Essa aliás é uma questão interessante: um Es- tado brasileiro socialista produziria uma estrutura urbana nacional diferente, com uma distribuição mais homogênea da população sobre o território, ou, pelo menos, acarretaria uma atenuação das tendências concentradoras de ocupação?

Muito provavelmente, não, na medida que a magnitude da concentração urbana tem mais a ver com as tecnologias de organização social e a sobrevivência das grandes populações do que com a ideologia das nações. Indo mais longe, existe uma relação funcional ou de necessidade entre concentração espacial e concentração de renda?

A quantificação, ainda que rápida, dos custos de urbanização da sociedade brasileira mostra os primeiros contornos e dimensões dos fenômenos em processo e leva à idéia de que a economia brasileira não parece ser capaz de gerar os excedentes necessários à solução de seus problemas urbanos ao nivel reclamado pela sociedade que pressiona o Estado e exige cada vez mais e melhores espaços, obras, equipamentos e serviços. Essa situação se agrava, na medida em que do Estado se exige não apenas infra-estrutura e equipamentos básicos mas ainda serviços e emprego.

Basta dizer que os custos de instalação e construção de uma cidade de padrões médios e mesmo baixos são da ordem de 5 mil dólares por habitante e os investimentos para gerar emprego, de 100 mil dólares por emprego - número modesto em relação aos níveis da Amazônia, que atingem 400 mil dólares ou mais por emprego criado no setor industrial ou de mineração. Assim, a sociedade brasileira estará exigindo do Estado, ou melhor, de si mesma - 
daí a importância de uma economia remuneradora de seus fatores e de elevado produto per capita recursos de ordem de US\$300 $\$ 10^{9}$ em vinte anos, além dos déficits anuais acumulados, e excluída a terra e a operação dos serviços, os equipamentos e serviços mais sofisticados como metrô, universidade e administração pública.

Assim, é dispensável demonstrar que as exigências em termos de quantidade e qualidade de serviços expressas ou latentes são incompatíveis com os recursos da sociedade e do Estado. Diz-se, com freqüência, que as grandes cidades mais ricas do mundo, como Nova York por exemplo, estão falidas. São, portanto, movimentos sociais urbanos de reivindicação e pressão organizados, sem a menor possibilidade de atingir seus objetivos, que desperdiçam energias populares em ações 'divergentes' que conduzem ao desalento, constituem uma duvidosa orientação política, pouco atraente, que à própria massa parecerá irreal, inútil e mesmo perigosa. Exigem esforços, sacrifícios e coragem por ganhos que não podem imaginar ou não podem crer...

Não obstante, os problemas a solucionar são inúmeros e graves. Como resolvê-los, sem recursos?

A hipótese inicial é que as cidades crescem enquanto constituem melhor alternativa. As cidades maiores são melhores que as menores e estas do que a área rural, e os seus diferenciais de crescimento espressam sempre opções de contingentes migratórios que enfrentam grandes sacrifícios na mudança.

O crescimento urbano rápido, entretanto, à exceção das cidades novas de apoio a empreendimentos programados, não ençontrará jamais uma infraestrutura perfeita à espera. Uma cidade que recebe a invasão de 500 mil habitantes novos por ano, como São Paulo, não pode recebê-los com ruas asfaltadas, casas, luz, esgotos, água, creche, parques infantis, hospitais, praças, jardins, abastecimento, segurança, administração pública, transporte coletivo e, sobretudo, emprego. Se tivesse recursos ociosos, seriam utilizados provavelmente e em primeiro lugar, logicamente, com as populações anteriormente radicadas, contribuintes carentes, zelosos de direitos inquestionáveis, também intransigentes nas suas reivindicações à base política local estruturada.

Os recursos, contudo, são escassos e o que resulta é competição e conflito. Uma cidade proporciona ou dá a seus habitantes, e o faz discriminadamente na medida em que sua administraçăo - que representa as forças políticas predominantes antecedentes - compreenda que deva dar, ou que tenha 'vantagens' em dar e, quase sempre, os recémchegados são vistos como intrusos, usurpadores, pobres indesejáveis, ou inimigos, aqueles que vêm perturbar a ordem existente e que constituem 'pro- blema social'. Sua integração e atendimento lou empulhação) estaria na dependência direta de sua capacidade de votar, ou, o que é mais remoto, de ameaçar.

Isso se evidencia nos inquéritos à população de baixa renda, de estabelecimento antigo, em cidades que passaram por certo período de estagnação, como Campinas, em 1969, e Piracicaba, em 1972, que revelam sempre muita hostilidade ao imigrante, ao operário novo e às novas indústrias.

Portanto, nada mais 'natural' que as cidades sejam processos dinâmicos em relativo equilíbrio, que incluem grandes contrastes, carências e conflitos, que vão se resolvendo e renovando no bojo de sua história cotidiana e sendo substituídos por novos. Não se pode falar em crise urbana. A cidade é um fato cultural e social. Nenhuma cidade pode ser melhor que a sociedade. Ela será sempre uma expressão da ordem social e econômica, produto de seu produto e da ideologia social que os partilha.

A responsabilidade dos diversos níveis de governo no provimento do trabalho e condições de vida das populações, hoje expressivamente urbanas, implica na precedência dos fatos e relações econômicas como fundamentos dos resultados sociais, na dependência entre o desempenho social e a qualidade ambiental e a base econômica e seus resultados. Nesse contexto emergem relações políticas que serão, também, uma expressão do desenvolvimento econômico-social e que vão agir, por sua vez, novamente, sobre a sociedade como um todo, sua economia e ideologia, constituindo um complexo de transformações dinâmicas inter-relacionadas nos planos econômico, social e político.

A grande metrópole contemporânea nos assombra. Sejam Nova York, Londres, Paris, Roterdam - sobre Moscou, Pequim, Shangai, faltam dados - ou São Paulo, Rio, Buenos Aires, Nova DeIhi, parecem ingovernáveis e definitivamente insolventes. Crescendo sem parar, contra tudo e contra todos, inclusive contra todos os planos qüinqüenais e peenedês caboclos e, com elas, apesar de condenadas e perseguidas, as esperanças de milhões de pessoas, que maximizam cotidianamente, enquanto imigrantes, suas alternativas.

Muitas vezes menciona-se como argumento de políticas descentralizadoras que investem, um pouco às tontas, nas cidades de porte médio ou regiões-problema, que investir nas metrópoles maiores vai acentuar os movimentos migratórios. Isso parece evidente e constitue um problema difícil e adicional a considerar. Mas, na verdade, não têm esses programas acarretado os efeitos pretendidos, a população continua emigrando mais para as supercidades supercarentes, ao mesmo tempo em que in- 
vestimentos a fundo perdido, nas áreas deprimidas, se perdem na ociosidade.

Enquanto em São Paulo a maior concentração de população nordestina não dispõe dos serviços mais elementares, milhares de conjuntos residenciais desocupados estão em ruínas por todo o Nordeste, notadamente nos estados do Ceará, Pernambuco e Bahia. Sob o pretexto de atendê-los, não se estará mantendo empregos não reprodutivos, ilusórios, estimulando perversamente a população a ficar, no maior interesse dos empregadores locais?

Apesar de tudo, as grandes cidades são o produto mais extraordinário da cultura conteporânea. Parecem irreversíveis. Nada as contem. O terceiro milênio será o milênio das megametrópoles - abertas - complexas, quase contínuas - informáticas. Temos que aprendê-las, formá-las conosco e formarnos com elas, cientes dos aspectos fundamentais que passamos a enumerar:

a) Os recursos naturais e financeiros necessários à nossa sobrevivência serão escassos, sobretudo para os países subdesenvolvidos.

b) As cidades serão imensas conurbações de massa humana economicamente homogênea, talvez até, no início, pobre, que expressarão novas culturas, novas relações de poder; serão dirigidas por sistemas políticos de tipo novo, nada terão a ver com as cidades peremptas aristocrático-burguesas - de classe média - sonhadora - ascendente, como Londres e Paris, ou suas réplicas formais como Buenos Aires, certas áreas do Rio e São Paulo e da cidade do Cabo.

c) A demagogia e o populismo estarão sepultos. Em seu lugar haverá uma sociedade urbana cada vez mais informada e, por isso, dona de si mesma; única responsável pelo seu produto e pelo seu destino.

Não haverá mais políticos de elite declamando, com eficiência retórica, compaixão pelas massas e reconhecimento de seus direitos - que, aliás, não existem, a não ser partindo-se de sua consciência e da sua ação. O paternalismo estará ultrapassado, falido como ineficiência social. Não serão prometidas aos habitantes das periferias, creches vazias de tijolos ordinários e úmidos como pagamento de votos, nem se proclamarão governos de participação, porque as nações serão verdadeiramente democráticas, política, social e economicamente. Não existirá a palavra subsídio, que terá sido forma de mentira das 'democracias' do século $X X$.

d) Os homens terão aprendido a aproveitar os recursos naturais e os partilharão com sabedoria e modéstia, para sobreviver com grandeza.

e) A inteligência humana refulgirá na plenitu- de de sua potencialidade e construirá um mundo harmonioso supratécnico e eficiente, preservando equilibradamente a natureza, o.ambiente artificial e a cultura criadas pelo homem.

Técnicos e políticos têm procurado encontrar fórmulas capazes de modificar as tendências concentradoras de população. Revelando, às vezes, uma visão extremamente preconceituosa, voltam as costas às realidades à sua frente e propõem soluções impossíveis, para as quais conseguem carrear importantes recursos - que são desperdiçados - , atenção e respeito. Como não perceber que a manutenção da população no campo, ou dispersa em pequenos núcleos, é inviável tanto pelo seu altíssimo custo social relativo como pela qualidade inferior e que todas as tentativas nesse sentido serão inúteis.

A proposta de criar cidades ao longo das rodovias como propôs o ex-prefeito Jaime Lerner, de Curitiba, é totalmente insustentável, não resiste à menor análise, não obstante o senso de responsabilidade e a competência de seu autor.

Menciona-se que os recursos naturais necessários para os 30 milhões de habitantes de São Paulo e os 70 milhões do eixo Rio - São Paulo, no ano 2000 , serão insuficientes ou obtidos a custos tão elevados que os inviabilizariam. Porém, quanto aos custos, não há estudos convincentes e conclusivos. Ao contrário, à primeira vista, a concentração populacional (condição não suficiente) e de investimentos parece ser condição necessária de enriquecimento social e desenvolvimento nacional. A Alemanha, Inglaterra, França e Itália possuem duas ou três vezes a população do estado de São Paulo, em área aproximadamente igual, com um nivel de controle ambiental, equilíbrio ecológico e qualidade urbana extraordinários, repartidos socialmente. O Japão, com uma densidade cinco vezes maior, está construindo uma organização econômica, social, política, cultural e urbana do mais alto nível que se conhece, num período de pouco mais de trinta anos, após ter sido derrotado e arrasado pela guerra.

As tendências não deixam dúvidas. O fracasso e desperdício das tentativas de reversão levaram um grande número de pessoas, nos últimos anos, a trabalhar na procura de novas soluções e novos desenhos.

Com a difusão da informação, o aprendizado e a consolidação da sociedade democrática, compreende-se que os recursos públicos e os bens urbanos têm que ser distribuídos igualmente e cobrados segundo critérios mais exigentes de justiça tributária.

Há evolução radical no que respeita aos critérios elitistas de uso do solo, aos conceitos e dimencionamentos permitidos, procurando assumir a rea- 
lidade, substituindo o sanitarismo subjetivo e perdulário por tecnologias novas mais eficazes e possíveis.

É preciso, entretanto, admitir, que a maioria dos países enfrentará dificuldades imensas para administrar seus recursos naturais, humanos e financeiros insuficientes. As dificuldades maiores serão as da população de baixa renda, mas a casa em si não será o maior problema, nem o mais importante.

Haverá a possibilidade de uma série de hipóteses possíveis de implementar, como a auto-ajuda, facilitada pela produção industrial de componentes baratos.

Mais complicado, notadamente nos países capitalistas, será o problema da terra, enquanto disponibilidade, dimensionamento, organização e projeto. Haverá problemas de loteamento e instrumentação legal, porém o progresso da arquitetura e da engenharia já permite lidar economicamente com as áreas acidentadas onde os terrenos são baratos mas a construção é cara. Há inovações quanto aos aspectos físicos de implementação e grande progresso vem-se fazendo em relação à comercialização e ao financiamento operados por instituições de tipo novo quanto às proporções, estruturas, conceitos e métodos.

No campo da produção e conservação de energia evoluiu-se expressivamente, sobretudo nos paises frios e sob a pressão da crise do petróleo que tem influído e redirecionado decisões relacionadas com a circulação e os transportes urbanos.

Procura-se criar e desenvolver tecnologias e desenhos da maior racionalidade para a solução dos problemas de abastecimento de água, esgoto e drenagem. São múltiplas e diversificadas as abordagens.

Estuda-se a substituição das tubulações de esgoto de dejetos e poluentes, por processos de tratamento local, incineração ou químicos. De uma maneira geral, as tubulações são consideradas inexeqüíveis pelo seu custo inicial e dispendiosa manutenção.

A drenagem de águas pluviais por rede subterrânea será proscrita e admitida apenas excepcionalmente. Serão utilizados sistemas superficiais, admitindo-se que não venha a ter importância que ocasionalmente se molhe os pés, numa pequena enxurrada, uma ou duas vezes ao ano. Melhor que catastróficas inundações ocasionadas por obsolescência ou obstrução de tubulações abandonadas sem manutenção. Mudarão os hábitos sociais para conviver com menos quantidade de água per capita. Os padrões de fornecimento diário de hoje, que oscilam entre 200 e 600 litros por pessoa, baixarão a 50 ou menos, modificando radicalmente conceitos de hi- giene pessoal e social que serão controladas por processos novos.

Serão adotadas tecnologias simples para redução do diâmetro das tubulações e da pressão do líquido nas redes. O uso de caixa d'água será universalizado, a reservação ficará sujeita a políticas de defesa dos interesses coletivos e o fornecimento poderá ser descontínuo. Utilizar-se-ão sistemas múltiplos e inter-relacionados de captação, com maior utilização dos lençóis profundos preservados.

No setor viário vão ser utilizadas pavimentações econômicas e se procederá a uma racionalização do sistema, pela redução de distâncias físicas e hierarquização das ruas.

As casas serão organizadas em grupos, com grande economia de espaço, permitindo associação em torno de sistemas evolutivos que possam ser aprimorados à medida em que os terrenos aumentem de uso e valor.

Muitas hipóteses se fazem em relação ao desenvolvimento social, ao aumento da população em função de melhoria da infra-estrutura, das condições de higiene, de emprego e dos níveis de instrução e educação. Considera-se que as altas taxas de natalidade precisariam ser controladas e tenderão a cair, já na década de 1980.

Haverá uma mudança fundamental no que respeita aos conceitos, substituídos os da classe média afluente pelos que interessem às grandes massas de população.

Muito será investido em educação que facilite a conscientização em torno das soluções técnicas e baratas e à interação das classes sociais, resolvendo conflitos, produzindo novos pactos e consensos, numa convivência pluralista e democrática de elevada participação política.

Finalmente, o desenho das cidades que abrigarão essa soiedade, porque ele é indispensável, alguém o fará. Certamente os niveis de interpretação das necessidades sociais serão mais elevados na medida em que muitos profissionais de várias áreas interfiram e que arquitetos competentes, sensíveis e modestos sejam convocados. Modéstia, sim, porque é uma qualidade fundamental para conhecer e para colocar a procura do resultado social ao abrigo das pretenções narcíseas do artista. E então beleza, qualidade e valor terão outras origens.

Nota - As idéias expostas neste artigo tem sido debatidas em inúmeros seminários: no Instituto de Arquitetos do Brasil, em São Paulo e Rio de Janeiro; na Federación Argentina de Asociaciones de Arquitectos, em Buenos Aires; no Massachusets Institute of Technology, nos Estados Unidos; na Universidade de Osaka, no Japão; e no Forum Architecture, Communication, Territoire, em Lausanne, na Suiça. O que aqui é dito se constitue num resumo da opiniões e preocupações centrais existentes sobre o futuro da urbanização brasileira. 